\title{
An Integrated Supplier-Buyer Inventory Model with Conditionally Free Shipment under Permissible Delay in Payments
}

\author{
Chia-Hsien Su \\ Department of Business Administration, Tungnan University, ShenKeng, Taipei 222, Taiwan \\ Correspondence should be addressed to Chia-Hsien Su, peony@mail.tnu.edu.tw
}

Received 3 March 2010; Accepted 22 June 2010

Academic Editor: Ferhan M. Atici

Copyright (C) 2010 Chia-Hsien Su. This is an open access article distributed under the Creative Commons Attribution License, which permits unrestricted use, distribution, and reproduction in any medium, provided the original work is properly cited.

It is well known that production, distribution, marketing, inventory control, and financing all/each have a positive impact on the performance of a supply chain. Despite the growing interest in the development of integrated inventory models, the interactions between these elements of a supply chain may not be efficiently included, resulting in a restricted supply chain model presentation. To incorporate this phenomenon, a mathematical model that tackles the interdependent relationships between these aforementioned elements is developed in this paper. This study considers the determination of the optimal pricing, ordering, and delivery policies of a profit-maximizing supply chain system, faced with (1) unit wholesale price of the supplier is set based on unit production cost, (2) unit production cost is taken as a function of demand rate and production rate, (3) the supplier's production rate is adjusted according to market demand, (4) market demand depends upon buyer's selling price, (5) a free freight is offered if the buyer's order exceeds a certain minimum requirement, and (6) a constant credit period is offered by the supplier to stimulate the demand of the buyer. Algorithm for computing the optimal policies is derived. The sensitivity of the optimal results with respect to those parameters which directly influence the production and transportation costs is also examined.

\section{Introduction}

Following the assumption in Harris's model [1], most traditional inventory models assumed that the production rate is constant. However, with advanced manufacturing technologies, such as Computer-aided design/manufacturing (CAD/CAM), flexible manufacturing system (FMS), and computer-integrated manufacturing system (CIMS), modem manufacturing industries are highly flexible, intelligent, and integrated. As stated by Schweitzer and Seidmann [2], today it is not difficult to adjust the mechanical productivity. Over the years, 
a number of papers have been published dealing with economic order quantity problems under conditions of variable production rate, such as Goswami and Chaudhuri [3], Balkhi and Benkherouf [4], Goyal and Giri [5], Bhunia and Maiti [6], Kalir and Arzi [7], Rahim and Ben-Daya [8], Giri et al. [9], and Öner and Bilgiç [10]. Recently, Li et al. [11] developed an economic production quantity-(EPQ)-based model with planned backorders to evaluate the impact of the postponement strategy on a manufacturer in a supply chain.

Transportation cost is another important but often overlooked feature of real inventory systems. Transportation costs are a critical part of the total logistics costs of a commodity. Given today's intense market competition, an appropriate transportation cost function should be included into lot-sizing research and modeling with all other appropriate costs. Tersine and Toelle [12] first established an economic inventory-transport model with freight discounts. Subsequent numerous studies on transportation cost have been published, for instance, Lee [13], Hwang et al. [14], Tersine and Barman [15], Russell and Krajewski [16], Shinn et al. [17], Swenseth and Godfrey [18] and Abad and Aggarwal [19]. Recently, Rieksts and Ventura [20] consider using both truckload (TL) transportation and less than truckload (LTL) transportation to fill order for inventory models that assume a constant demand rate that must be met without shortages.

However, the above research mainly focuses on operational aspects but neglects financial concens that firms may face when deciding the supply chain method. In real business environments, many firms are capital constrained and need to finance their operations from external capital markets. Today, payment within a specified period after delivery, usually called trade credit, is a widely observed pricing strategy for improving the profitability and cost effectiveness in sales (e.g., [21-23]). Suppliers offer a trade credit as an incentive to increase sales and reduce stock, and the buyer can use the sale revenue to benefit without interest charged during the credit period. Goyal [24] is the first one who developed an EOQ model under the condition of permissible delay in payments. Numerous other studies on trade credit have since been published including Aggarwal and Jaggi [25], Jamal et al. [26], Chang and Dye [27], Teng [28], Arcelus et al. [29], Biskup et al. [30], Chang et al. [31], Huang [32], Chang [33], Chung et al. [34], Ouyang et al. [35], Teng et al. [36], Chung and Liao [37], and Sarmah et al. [38].

The above articles have investigated the effect on inventory policy under trade credit from the perspective of the buyer (or supplier) only. However, decisions made by channel members are interdependent which determine the performances of other members as well as the entire channel. For example, a buyer's selling price decision will influence the customer demand and therefore the buyer's and supplier's sales volumes. As the buyer's order quantity decision based on customer demand will alter the supplier's production decision, while the supplier offers trade credit to encourage sales, the decisions on inventory and pricing of the supply chain will be altered after a while. Therefore, to improve the collaboration of supply chain partners, determining the optimal policies based on the integrated total profit function is more reasonable than using the buyer or the supplier's individual profit functions. Some scholars have noted this fact and worked on developing supply chain management decision models. Abad and Jaggi [39] developed ajoint approach to determine the optimal unit price and the length of the credit period when end demand is price sensitive under permissible delay in payments. Jaber and Osman [40] proposed a centralized model where players in a two-level supply chain coordinate their orders to minimize their local costs and that of the entire chain. Yang and Wee [41] considered an optimal replenishment policy with a credit term in a collaborative deteriorating inventory system when the demand is price sensitive and the replenishment rate is finite. Sheen and 
Table 1: Comparison between the papers discussing integrated inventory model with a trade credit.

\begin{tabular}{|c|c|c|c|c|c|}
\hline Author(s) & $\begin{array}{l}\text { Demand } \\
\text { rate }\end{array}$ & $\begin{array}{l}\text { Production } \\
\text { rate }\end{array}$ & $\begin{array}{l}\text { Production/purchase } \\
\text { cost }\end{array}$ & Freight rate & $\begin{array}{l}\text { Wholesale } \\
\text { price }\end{array}$ \\
\hline $\begin{array}{l}\text { Abad and } \\
\text { Jaggi [39] }\end{array}$ & $\begin{array}{l}\text { Retail price } \\
\text { sensitive }\end{array}$ & Constant & Constant & - & Constant \\
\hline $\begin{array}{l}\text { Jaber and } \\
\text { Osman [40] }\end{array}$ & Constant & - & - & - & Constant \\
\hline $\begin{array}{l}\text { Yang and } \\
\text { Wee [41] }\end{array}$ & $\begin{array}{l}\text { Retail price } \\
\text { sensitive }\end{array}$ & - & Constant & - & Constant \\
\hline $\begin{array}{l}\text { Sheen and } \\
\text { Tsao [42] }\end{array}$ & $\begin{array}{l}\text { Retail price } \\
\text { sensitive }\end{array}$ & - & Constant & $\begin{array}{l}\text { Quantity } \\
\text { discounts are } \\
\text { offered }\end{array}$ & Constant \\
\hline $\begin{array}{l}\text { Chen and } \\
\text { Kang [43] }\end{array}$ & Constant & - & - & - & Constant \\
\hline Su et al. [44] & $\begin{array}{l}\text { Customer's } \\
\text { credit period } \\
\text { sensitive }\end{array}$ & Constant & Constant & - & Constant \\
\hline $\begin{array}{l}\text { Ouyang et } \\
\text { al. [45] }\end{array}$ & $\begin{array}{l}\text { Retail price } \\
\text { sensitive }\end{array}$ & $\begin{array}{l}\text { Adjust with } \\
\text { demand rate }\end{array}$ & Constant & $\begin{array}{l}\text { Quantity } \\
\text { discounts are } \\
\text { offered }\end{array}$ & Constant \\
\hline Ho et al. [46] & $\begin{array}{l}\text { Retail price } \\
\text { sensitive }\end{array}$ & $\begin{array}{l}\text { Adjust with } \\
\text { demand rate }\end{array}$ & Constant & - & Constant \\
\hline This paper & $\begin{array}{l}\text { Price } \\
\text { sensitive }\end{array}$ & $\begin{array}{l}\text { Adjust with } \\
\text { demand rate }\end{array}$ & $\begin{array}{l}\text { Production and } \\
\text { demand sensitive }\end{array}$ & $\begin{array}{l}\text { Conditionally } \\
\text { free shipment }\end{array}$ & $\begin{array}{l}\text { Production } \\
\text { cost } \\
\text { related }\end{array}$ \\
\hline
\end{tabular}

"_" denotes the factor is not considered in the model.

Tsao [42] explored how channel coordination can be achieved using trade credit. Chen and Kang [43] developed integrated models for determining the optimal replenishment time interval and replenishment frequency. Su et al. [44] considered a seller-buyer channel in which the end demand is credit period sensitive. Recently, Ouyang et al. [45] and Ho et al. [46] considered an optimal replenishment and order policy with a credit term when the demand is price sensitive and the production is rate sensitive demand.

In this study, to analyze pricing, ordering, delivery, and trade credit with comprehensive considerations of operation, marketing, and financing among channel members, a supplier-buyer inventory model is developed. We assume the supplier's unit selling price is based on his/her unit production cost which is decided by the market demand and production rates. And the production rate is adjusted with a price-sensitive market demand. In such circumstances the unit wholesale price, reflecting the costs of the product, imposed by the seller on the buyer, does influence the end demand for the product. In addition, the supplier offers to pay freight charges if an order quantity meets or exceeds a certain minimum requirement. Furthermore, a fixed trade credit period is offered by the supplier. In this paper, we maximize the total profit of the whole supply chain (i.e., treating the supply chain as a single level profit centre). An algorithm is developed to determine the optimal ordering, shipping, and pricing policy. Numerical examples with relevant data are devoted to find the optimal policies of the developed model. Sensitivity analysis for main parameters is also conducted. The major difference between our model and other related models is shown in Table 1. 


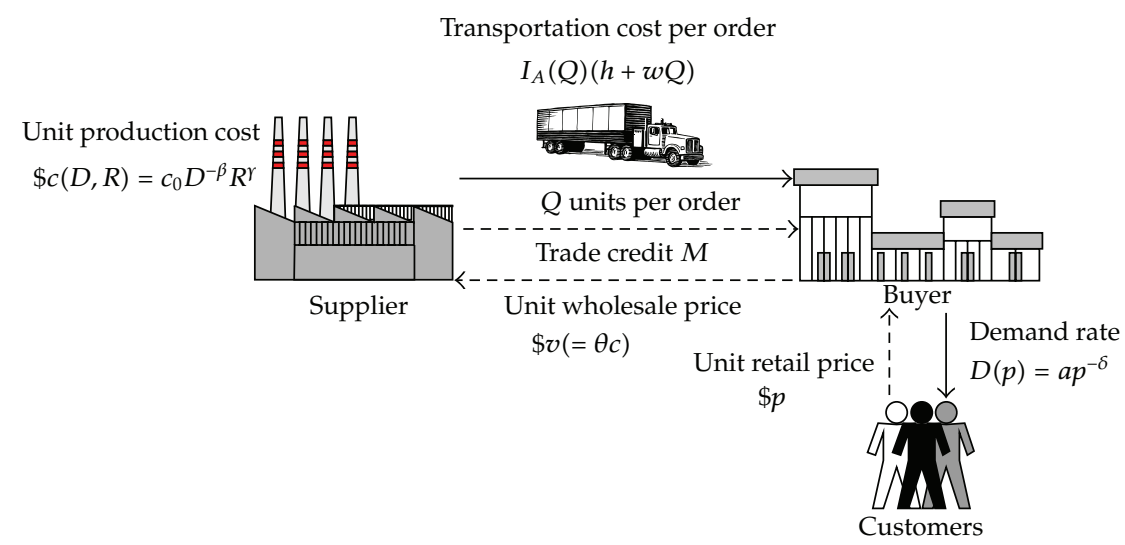

Figure 1: The supply chain system.

\section{Mathematical Formulation}

In this section, we consider an integrated inventory model with a retail price sensitive demand, where the supplier offers to pay freight charges if an order quantity exceeds or equal to a certain minimum requirement. In addition, a certain credit period is provided to the buyer. The relationship among members in this supply chain system is illustrated in Figure 1. To formulate the integrated inventory model, the supplier's total profit per unit time is discussed first. Then the buyer's total profit per unit time is discussed.

\subsection{Supplier's Total Profit per Unit Time}

During the production period, the supplier manufactures in batches of size $n Q$, where $n$ is an integer, and incurs a batch setup cost $S_{V}$. The production cycle length is $n Q / D=n T$. Once the first $Q$ units are produced, the supplier delivers them to the buyer and then continuously making the delivery on average every $T$ units of time until the supplier's inventory level falls to zero. Therefore, the setup cost per unit time is $S_{V} /(n T)$.

The inventory holding cost contains two components: unit holding cost and opportunity cost. The unit holding cost relates to the actual ownership of the goods and includes storage and maintenance expenses, which is accounted on a per-unit-of-inventory basis. The opportunity holding cost is charged on the money value of the inventory on hand. The supplier's inventory per unit time is given by

$$
\left\{n Q\left[\frac{Q}{R}+(n-1) \frac{Q}{D}\right]-\frac{n^{2} Q^{2}}{2 R}-\frac{Q^{2}}{D}[1+2+\cdots+(n-1)]\right\} / \frac{n Q}{D}=\frac{D T}{2}[(n-1)(1-\rho)+\rho],
$$

where $\rho=D / R$.

Note that the similar derivation of supplier's average inventory using a manufacturing lot size of $Q$ units can be found in Joglekar [48]. With production cost per unit $c$, the holding cost rate excluding interest charges $r_{V}$ and the capital opportunity cost per dollar per unit time $I_{V p}$, the supplier's holding cost per unit time is $c\left(r_{V}+I_{V p}\right) D T[(n-1)(1-\rho)+\rho] / 2$. 
Because of offering a credit period $M$ to the buyer, the supplier endures a capital opportunity cost $v I_{V p} D M=\theta c I_{V p} D M$ within the time gap between delivery and payment received of the product. The supplier determines unit wholesale price $\$ v(=\theta c)$ based on unit production cost $\$ c$, therefore the sales revenue per unit time is $(v-c) D=(\theta-1) c D$. In addition, to encourage order more, if the buyer's order quantity $Q \geq \psi$, the supplier is required to pay the transportation cost per unit time $\left(1-I_{A}(Q)\right)(h+w Q) / T$.

Therefore, the supplier's total profit per unit, which is the sales revenue minus set-up cost, holding cost, capital opportunity cost, and transportation cost, can be written as follows:

$$
\begin{aligned}
\operatorname{TV} P(n)= & c D\left\{(\theta-1)-\frac{\left(r_{V}+I_{V p}\right) T}{2}[(n-1)(1-\rho)+\rho]-\theta I_{V p} M\right\} \\
& -\frac{\left(1-I_{A}(Q)\right)(h+w Q)}{T}-\frac{S_{V}}{n T} .
\end{aligned}
$$

\subsection{Buyer's Total Profit per Unit Time}

For the buyer, the total sales profit per unit time is given by $(p-v) D=(p-\theta c) D$ and the ordering cost per unit time is $S_{B} / T$. With the unit purchasing cost $v$, the holding cost rate $r_{B}$, and the average inventory over the cycle $Q / 2$, the buyer's holding cost (excluding interest charges) per unit time is $v r_{B} Q / 2=\theta c r_{B} D T / 2$. The transportation cost per unit time is $I_{A}(Q)(h+w Q) / T$.

As the payment is done before or after the total depletion of inventory, we have the following two possible cases: (i) $T \leq M$, and (ii) $T \geq M$.

Case $1(T \leq M)$. In this case, as the permissible payment time expires on or after the inventory is depleted completely, the buyer pays no opportunity cost for the purchase items. Through the credit period, buyer sells the products and uses the sales revenue to earn interest at a rate of $I_{B e}$. Thus, the interest earned per unit time is

$$
\frac{1}{T}\left[p I_{B e} \int_{0}^{T} D t d t+p I_{B e} D T(M-T)\right]=D p I_{B e}\left(M-\frac{T}{2}\right) .
$$

Case $2(T \geq M)$. When buyer's permissible payment time expires on or before the inventory is depleted completely, the buyer can sell the items and earn interest with rate $I_{B e}$ until the end of the credit period $M$. Thus, the interest earned per unit time is $\left(p I_{B e} / T\right) \int_{0}^{M} D t d t=$ $D p I_{B e} M^{2} / 2 T$. On the other hand, the buyer still has some inventory on hand when paying the total purchasing amount to the supplier. Hence, for the items still in stock, buyer endures a capital opportunity cost at a rate of $I_{B p}$; the opportunity cost per unit time for the items is obtained by $\left(v I_{B p} / T\right) \int_{M}^{T} D(T-t) d t=\theta c I_{B p} D(T-M)^{2} / 2 T$.

Therefore, the total profit per unit time for the buyer, which is the sales profit plus the interest earned, minus the total relevant costs, composed of ordering cost, holding cost, opportunity cost and transportation cost, can be expressed as follows:

$$
T B P(p, T)= \begin{cases}T B P_{1}(p, T), & T \leq M, \\ T B P_{2}(p, T), & T \geq M,\end{cases}
$$


where

$$
\begin{gathered}
T B P_{1}(p, T)=D\left\{p-\theta c\left(1+\frac{r_{B} T}{2}\right)+p I_{B e}\left(M-\frac{T}{2}\right)\right\}-\frac{I_{A}(Q)(h+w Q)}{T}-\frac{S_{B}}{T} \\
T B P_{2}(p, T)=D\left\{p-\theta c\left[1+\frac{r_{B} T}{2}+\frac{I_{B p}(T-M)^{2}}{2 T}\right]+\frac{p I_{B e} M^{2}}{2 T}\right\}-\frac{I_{A}(Q)(h+w Q)}{T}-\frac{S_{B}}{T} .
\end{gathered}
$$

\section{Theoretical Results}

Once the supplier and buyer have established a long-term strategic partnership and are contracted to commit to the relationship, they will determine the best joint policy in which to cooperate. Under this circumstance, joint total profit per unit time for the supplier and buyer is

$$
\Pi(n, p, T)= \begin{cases}\Pi_{1}(n, p, T), & T \leq M, \\ \Pi_{2}(n, p, T), & T \geq M,\end{cases}
$$

where

$$
\begin{aligned}
& \Pi_{1}(n, p, T)=T V P(n)+T B P_{1}(p, T) \\
& =D\left\{p-w-c\left[1+\theta I_{V p} M+\frac{T}{2}\left(\theta r_{B}+\varphi\right)\right]+p I_{B e}\left(M-\frac{T}{2}\right)\right\}-\frac{\bar{S}}{T}, \\
& \Pi_{2}(n, p, T)=\operatorname{TVP}(n)+T B P_{2}(p, T) \\
& =D\left\{p-w-c\left\{1+\frac{\varphi T}{2}+\theta\left[\left(I_{V p}-I_{B p}\right) M+\frac{I_{B p} M^{2}}{2 T}+\frac{T\left(r_{B}+I_{B p}\right)}{2}\right]\right\}\right. \\
& \left.+\frac{p I_{B e} M^{2}}{2 T}\right\}-\frac{\bar{S}}{T} \\
& \bar{S}=\frac{S_{V}}{n}+S_{B}+h, \quad \varphi=\left(r_{V}+I_{V p}\right)[(n-1)(1-\rho)+\rho] .
\end{aligned}
$$

Note that $\Pi_{1}(n, p, M)=\Pi_{2}(n, p, M)$, hence joint total profit per unit time $\Pi(n, p, T)$ is continuous at point $T=M$ for fixed $n$ and $p$.

To find the optimal solution, say $\left(n^{*}, p^{*}, T^{*}\right)$, that maximizes the above-integrated total profit, the following procedures are taken. First, for fixed $p$ and $T$, check the effect of $n$ on the joint total profit per unit time $\Pi(n, p, T)$ with the fact $\partial^{2} \Pi(n, p, T) / \partial n^{2}=\partial^{2} \Pi_{i}(n, p, T) / \partial n^{2}=$ $-2 S_{V} /\left(n^{3} T\right)<0, i=1,2, \Pi(n, p, T)$ is a concave function of $n$. Therefore, for fixed $p$ and $T$, the search for the optimal shipment number, $n^{*}$, is reduced to find a local optimal solution.

Case $1(T \leq M)$. For fixed $n$ and $p$, with $\partial^{2} \Pi_{1}(n, p, T) / \partial T^{2}=-2 \bar{S} / T^{3}<0, \Pi_{1}(n, p, T)$ is a concave function of $T$; hence, there exists a unique value of $T$ (denoted by $T_{1}(n, p)$ ) which 
maximizes $\Pi_{1}(n, p, T)$. By solving $\partial \Pi_{1}(n, p, T) / \partial T=-D\left[c\left(\theta r_{B}+\varphi\right)+p I_{B e}\right] / 2+\bar{S} / T^{2}=$ $0, T_{1}(n, p)$ can be obtained and is given as

$$
T_{1}(n, p)=\sqrt{\frac{2 \bar{S}}{D\left[c\left(\theta r_{B}+\varphi\right)+p I_{B e}\right]}} .
$$

To ensure $T_{1}(n, p) \leq M$, substituting (3.4) into this inequality results in

$$
\text { if } 2 \bar{S} \leq \Delta, \quad \text { then } T_{1}(n, p) \leq M,
$$

where

$$
\Delta=D\left[c\left(\theta r_{B}+\varphi\right)+p I_{B e}\right] M^{2} .
$$

Conversely, if $2 \bar{S}>\Delta$, we have

$$
\frac{\partial \Pi_{1}(n, p, T)}{\partial T}>\frac{D\left[c\left(\theta r_{B}+\varphi\right)+p I_{B e}\right]\left(M^{2}-T^{2}\right)}{2 T^{2}} \geq 0,
$$

which implies that $\Pi_{1}(n, p, T)$ is an increase function of $T \in(0, M]$. Hence, for fixed $n$ and $p, \Pi_{1}(n, p, T)$ has a maximum value at the boundary point $T=M$.

From the above results, we can easyily obtain the following lemma. The proof is omitted here.

Lemma 3.1. For any given $n$ and $p$,

(a) if $2 \bar{S} \leq \Delta$, then $T=T_{1}(n, p)$ is the optimal value which maximizes $\Pi_{1}(n, p, T)$.

(b) if $2 \bar{S}>\Delta$, then $T=M$ is the optimal value which maximizes $\Pi_{1}(n, p, T)$.

Case $2(T \geq M)$. The first order necessary condition with respect to $T$ for $\Pi_{2}(n, p, T)$ in (3.3) to be maximized is

$$
\frac{\partial \Pi_{2}(n, p, T)}{\partial T}=\frac{D}{2}\left\{-c\left[\theta\left(r_{B}+I_{B p}\right)+\varphi\right]+\frac{\left(c \theta I_{B p}-p I_{B e}\right) M^{2}}{T^{2}}\right\}+\frac{\bar{S}}{T^{2}}=0,
$$

then we obtain the value of $T$ (denoted by $\left.T_{2}(n, p)\right)$ as

$$
T_{2}(n, p)=\sqrt{\frac{2 \bar{S}+D\left(c \theta I_{B p}-p I_{B e}\right) M^{2}}{D c\left[\theta\left(r_{B}+I_{B p}\right)+\varphi\right]}} .
$$

To ensure $T_{2}(n, p) \geq M$, substituting (3.9) into this inequality results in the following:

$$
\text { if } 2 \bar{S} \geq \Delta \text {, then } T_{2}(n, p) \geq M, \quad \text { where } \Delta \text { is defined as above. }
$$


Note that when $2 \bar{S} \geq \Delta$ holds, then

$$
\begin{aligned}
2 \bar{S}+D\left(c \theta I_{B p}-p I_{B e}\right) M^{2} & \geq D\left[c\left(\theta r_{B}+\varphi\right)+p I_{B e}\right] M^{2}+D\left(c \theta I_{B p}-p I_{B e}\right) M^{2} \\
& =D\left\{c\left[\theta\left(r_{B}+I_{B p}\right)+\varphi\right]\right\} M^{2}>0
\end{aligned}
$$

holds, which implies that $T_{2}(n, p)$ in (3.9) is well defined. Besides, we can show that

$$
\frac{\partial^{2} \Pi_{2}(n, p, T)}{\partial T^{2}}=-\frac{\left[2 \bar{S}+D\left(c \theta I_{B p}-p I_{B e}\right) M^{2}\right]}{T^{3}}<0 .
$$

Hence, $T_{2}(n, p)$ in (3.9) is a unique value which maximizes $\Pi_{2}(n, p, T)$.

Conversely, if $2 \bar{S}<\Delta$, we have

$$
\begin{aligned}
\frac{\partial \Pi_{2}(n, p, T)}{\partial T} & <\frac{D}{2}\left\{-c\left[\theta\left(r_{B}+I_{B p}\right)+\varphi\right]+\frac{\left(c \theta I_{B p}-p I_{B e}\right) M^{2}}{T^{2}}\right\}+\frac{D\left[c\left(\theta r_{B}+\varphi\right)+p I_{B e}\right] M^{2}}{2 T^{2}} \\
& =\frac{D}{2}\left\{-c\left[\theta\left(r_{B}+I_{B p}\right)+\varphi\right]+\frac{c\left[\theta\left(r_{B}+I_{B p}\right)+\varphi\right] M^{2}}{T^{2}}\right\} \\
& \leq \frac{D}{2}\left\{-c\left[\theta\left(r_{B}+I_{B p}\right)+\varphi\right]+\frac{c\left[\theta\left(r_{B}+I_{B p}\right)+\varphi\right] M^{2}}{M^{2}}\right\}=0 .
\end{aligned}
$$

Thus, $\Pi_{2}(n, p, T)$ is a strictly decreasing function of $T \in[M, \infty)$, which implies that $\Pi_{2}(n, p, T)$ has a maximum value at the boundary point $T=M$ for fixed $n$ and $p$.

From the above results, we can easily obtain the following lemma. The proof is omitted here.

Lemma 3.2. For any given $n$ and $p$,

(a) if $2 \bar{S} \geq \Delta$, then $T=T_{2}(n, p)$ is the optimal value which maximizes $\Pi_{2}(n, p, T)$.

(b) if $2 \bar{S}<\Delta$, then $T=M$ is the optimal value which maximizes $\Pi_{2}(n, p, T)$.

Combining Lemmas 3.1 and 3.2, we obtain the following result.

Theorem 3.3. For any given $n$ and $p$,

(a) if $2 \bar{S} \leq \Delta$, the optimal replenishment cycle length is $T=T_{1}(n, p)$.

(b) If $2 \bar{S}>\Delta$, the optimal replenishment cycle length is $T=T_{2}(n, p)$.

Proof. It immediately follows from the facts that $\Pi_{1}(n, p, M)=\Pi_{2}(n, p, M)$, Lemmas 3.1 and 3.2. 
Next, let

$$
\begin{aligned}
f(p) & =2 \bar{S}-\Delta=2 \bar{S}-D\left[c\left(\theta r_{B}+\varphi\right)+p I_{B e}\right] M^{2} \\
& =2 \bar{S}-a p^{-\delta}\left[c_{0}\left(a p^{-\delta}\right)^{\gamma-\beta} \rho^{-\gamma}\left(\theta r_{B}+\varphi\right)+p I_{B e}\right] M^{2},
\end{aligned}
$$

and taking the derivative of $f(p)$ with respect to $p$, it gets

$$
\frac{d f(p)}{d p}=a p^{-\delta-1}\left[\frac{c_{0} \delta(\gamma-\beta+1)\left(a p^{-\delta}\right)^{\gamma-\beta}\left(\theta r_{B}+\varphi\right)}{\rho^{\gamma}}+(\delta-1) p I_{B e}\right] M^{2}>0
$$

because $0<\beta-\gamma<1$ and $\delta>1$. Therefore $f(p)$ is a strictly increasing function of $p$. Furthermore, we have $\lim _{p \rightarrow 0^{+}} f(p)=-\infty$ and $\lim _{p \rightarrow \infty} f(p)=2 \bar{S}>0$. Hence, a unique value $\hat{p}$ such that $f(\hat{p})=0$ exists, that is,

$$
a \widehat{p}^{-\delta}\left[\left(a \widehat{p}^{-\delta}\right)^{\gamma-\beta} c_{0} \rho^{-\gamma}\left(\theta r_{B}+\varphi\right)+\hat{p} I_{B e}\right] M^{2}=2 \bar{S}
$$

Thus, we have

$$
2 \bar{S} \leq \Delta \quad \text { iff } p \leq \hat{p}
$$

Based on the above arguments and Theorem 3.3, we can easily obtain the following lemma. The proof is omitted here.

Lemma 3.4. For any given $n$ and $p$,

(a) if $p \leq \hat{p}$, the optimal replenishment cycle length is $T=T_{1}(n, p)$,

(b) if $p>\hat{p}$, the optimal replenishment cycle length is $T=T_{2}(n, p)$.

From Lemma 3.4, when $n$ and $p$ are given, we can get the maximum joint total profit per unit time as follows:

$$
\Pi(n, p)= \begin{cases}\Pi_{1}\left(n, p, T_{1}(n, p)\right), & \text { if } p \leq \hat{p} \\ \Pi_{2}\left(n, p, T_{2}(n, p)\right), & \text { if } p>\hat{p}\end{cases}
$$


where

$$
\begin{aligned}
\Pi_{1}\left(n, p, T_{1}(n, p)\right)= & a p^{-\delta}\left[p\left(1+I_{B e} M\right)-w-\left(a p^{-\delta}\right)^{\gamma-\beta} c_{0} \rho^{-\gamma}\left(1+\theta I_{V p} M\right)\right] \\
& -\sqrt{2 a p^{-\delta} \bar{S}\left[\left(a p^{-\delta}\right)^{\gamma-\beta} c_{0} \rho^{-\gamma}\left(\theta r_{B}+\varphi\right)+p I_{B e}\right]}, \\
\Pi_{2}\left(n, p, T_{2}(n, p)\right)= & a p^{-\delta}\left\{p-w-\left(a p^{-\delta}\right)^{\gamma-\beta} c_{0} \rho^{-\gamma}\left[1+\theta\left(I_{V p}-I_{B p}\right) M\right]\right\} \\
& -\sqrt{\left(a p^{-\delta}\right)^{\gamma-\beta+1} c_{0} \rho^{-\gamma}\left[\theta\left(r_{B}+I_{B p}\right)+c \varphi\right]} \\
& \times \sqrt{\left\{2 \bar{S}+a p^{-\delta}\left[\left(a p^{-\delta}\right)^{\gamma-\beta} c_{0} \rho^{-\gamma} \theta I_{B p}-p I_{B e}\right] M^{2}\right\}} .
\end{aligned}
$$

Now, to obtain the optimal retail price $p$ which maximizes $\Pi(n, p)$ for fixed $n$, by taking the first-order partial derivative of $\Pi_{i}\left(n, p, T_{i}(n, p)\right), i=1,2$ in (3.19) and (3.20) with respect to $p$ and by setting the result to be zero, we have

$$
\begin{aligned}
& \frac{\partial \Pi_{1}\left(n, p, T_{1}(n, p)\right)}{\partial p}=a p^{-\delta}\left\{\frac{\delta}{p}\left[w+(1-\beta+\gamma)\left(a p^{-\delta}\right)^{\gamma-\beta} c_{0} \rho^{-\gamma}\left(1+\theta I_{V p} M\right)\right]\right. \\
& \left.+(1-\delta)\left(I_{B e} M+1\right)\right\} \\
& +\left\{\frac{\delta}{p}\left[(1-\beta+\gamma)\left(a p^{-\delta}\right)^{\gamma-\beta} c_{0} \rho^{-\gamma}\left(\varphi+\theta r_{B}\right)\right]-(1-\delta) I_{B e}\right\} \\
& \times \sqrt{\frac{\bar{S}}{2\left(\varphi+\theta r_{B}\right) c_{0}\left(a p^{-\delta}\right)^{\gamma-\beta-1} \rho^{-\gamma}+p I_{B e}}}=0, \\
& \frac{\partial \Pi_{2}\left(n, p, T_{2}(n, p)\right)}{\partial p}=\left\{\frac{a p^{-\delta} M^{2}\left\{(\delta / p)\left[(1-\beta+\gamma)\left(a p^{-\delta}\right)^{\gamma-\beta} c_{0} \rho^{-\gamma} \theta I_{B p}\right]+(1-\delta) I_{B e}\right\}}{\sqrt{\left\{2 \bar{S}+a p^{-\delta} M^{2}\left[\left(a p^{-\delta}\right)^{\gamma-\beta} c_{0} \rho^{-\gamma} \theta I_{B p}-p I_{B e}\right]\right\}}}\right. \\
& \left.-\frac{\delta}{p}(1-\beta+\gamma) \sqrt{\left\{2 \bar{S}+a p^{-\delta} M^{2}\left[\left(a p^{-\delta}\right)^{\gamma-\beta} c_{0} \rho^{-\gamma} \theta I_{B p}-p I_{B e}\right]\right\}}\right\} \\
& \times \frac{1}{2} \sqrt{\left[\varphi+\theta\left(r_{B}+I_{B p}\right)\right] c_{0}\left(a p^{-\delta}\right)^{\gamma-\beta+1} \rho^{-\gamma}}+a p^{-\delta}(1-\delta)+\frac{\delta}{p} \\
& \times\left\{w-(\gamma-\beta+1) c_{0}\left(a p^{-\delta}\right)^{\gamma-\beta+1} \rho^{-\gamma}\left[M \theta\left(I_{B p}-I_{V p}\right)-1\right]\right\}=0 .
\end{aligned}
$$


Eventually, we check the second-order condition $\partial^{2} \Pi_{i}\left(n, p, T_{i}(n, p)\right) / \partial p^{2}<0, i=1,2$, for concavity.

Therefore, we obtain the following result.

Theorem 3.5. For any given $n$,

(a) if there exists a value $p_{1}$ which satisfies the corresponding $\partial \Pi_{1}\left(n, p, T_{1}(n, p)\right) / \partial p=0$ in (3.21), $\partial^{2} \Pi_{1}\left(n, p, T_{1}(n, p)\right) / \partial p^{2}<0$ and $p_{1} \leq \hat{p}$, then $(p, T)=\left(p_{1}, T_{1}\left(n, p_{1}\right)\right)$ is the optimal solution such that $\Pi_{1}\left(n, p_{1}, T_{1}\left(n, p_{1}\right)\right)$ has a maximum value,

(b) if there exists a value $p_{2}$ which satisfies the corresponding $\partial \Pi_{2}\left(n, p, T_{2}(n, p)\right) / \partial p=0$ in (3.22), $\partial^{2} \Pi_{2}\left(n, p, T_{2}(n, p)\right) / \partial p^{2}<0$, and $p_{2}>\hat{p}$, then $(p, T)=\left(p_{2}, T_{2}\left(n, p_{2}\right)\right)$ is the optimal solution such that $\Pi_{2}\left(n, p_{2}, T_{2}\left(n, p_{2}\right)\right)$ has a maximum value.

Proof. It immediately follows from Lemma 3.4.

Summarizing the above arguments, an efficient algorithm for obtaining the optimal solution $\left(n^{*}, p^{*}, T^{*}\right)$ is depicted.

Algorithm 3.6.

Step 1 . Set $n=1$.

Step 2. Determine $\hat{p}$ from (3.16).

Step 3. Find $p_{1}$ which satisfies $p_{1} \leq \hat{p}, \partial \Pi_{1}\left(n, p, T_{1}(n, p)\right) / \partial p=0$ in (3.21) and $\partial^{2} \Pi_{1}(n, p$, $\left.T_{1}(n, p)\right) / \partial p^{2}<0$, then determine $T_{1}\left(n, p_{1}\right)$ by $(3.4)$ and calculate $\Pi_{1}\left(n, p_{1}, T_{1}\left(n, p_{1}\right)\right)$ by (3.19); otherwise, set $\Pi_{1}\left(n, p, T_{1}(n, p)\right)=0$.

Step 4. Find $p_{2}$ which satisfies the $p_{2}>\hat{p}, \partial \Pi_{2}\left(n, p, T_{2}(n, p)\right) / \partial p=0$ in (3.22) and $\partial^{2} \Pi_{2}(n, p$, $\left.T_{2}(n, p)\right) / \partial p^{2}<0$, then determine $T_{2}\left(n, p_{2}\right)$ by (3.9) and calculate $\Pi_{2}\left(n, p_{2}, T_{2}\left(n, p_{2}\right)\right)$ by $(3.20)$; otherwise, set $\Pi_{2}\left(n, p_{2}, T_{2}\left(n, p_{2}\right)\right)=0$.

Step 5. Find $\operatorname{Max}_{i=1,2}\left\{\prod_{i}\left(n, p_{i}, T_{i}\left(n, p_{i}\right)\right)\right\}$.

Set $\Pi^{(n)}\left(n, p^{(n)}, T^{(n)}\right)=\operatorname{Max}_{i=1,2}\left\{\Pi_{i}\left(n, p_{i}, T_{i}\left(n, p_{i}\right)\right)\right\}$, then $\left(p^{(n)}, T^{(n)}\right)$ is the optimal solution for this given $n$.

Step 6. Set $n=n+1$. Repeat Steps 2 to 5 to find $\Pi^{(n)}\left(n, p^{(n)}, T^{(n)}\right)$.

Step 7. If $\Pi^{(n)}\left(n, p^{(n)}, T^{(n)}\right) \geq \Pi^{(n-1)}\left(n-1, p^{(n-1)}, T^{(n-1)}\right)$, go to Step 6. Otherwise, go to Step 8 .

Step 8. Set $\Pi^{*}\left(n^{*}, p^{*}, T^{*}\right)=\Pi^{(n-1)}\left(n-1, p^{(n-1)}, T^{(n-1)}\right) .\left(n^{*}, p^{*}, T^{*}\right)$ is the optimal solution.

Once the optimal solution $\left(n^{*}, p^{*}, T^{*}\right)$ is obtained, the optimal order quantity $Q^{*}=$ $D\left(p^{*}\right) T^{*}$ follows.

\section{Numerical Examples and Discussion}

Example 4.1. In order to verify the proposed model, a numerical case will be used to demonstrate our model. We consider a company produces a product for an industrial client. It has experienced that the demand rate is price-relative. This item is produced with the market 


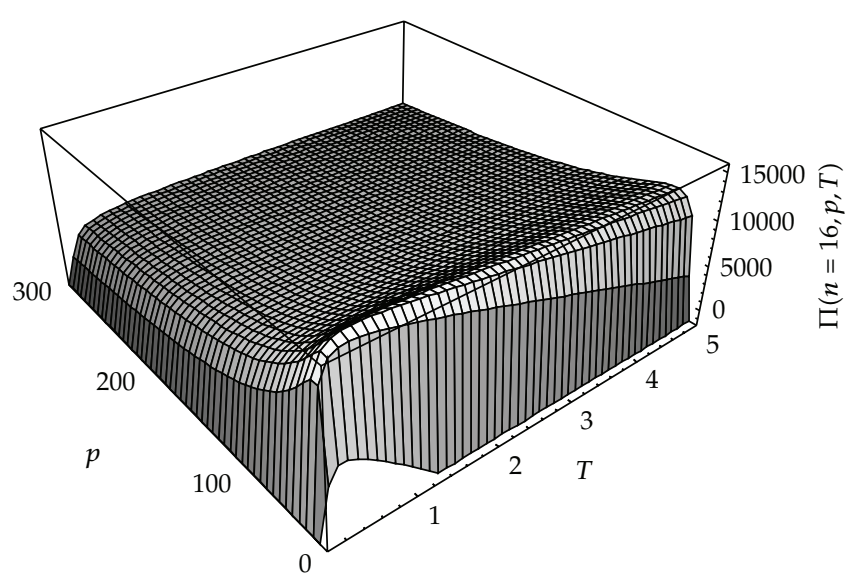

Figure 2: Concavity of the total profit function $\Pi^{(n)}(n, p, T)$ for fixed $n=16$.

demand. To increase sales, a credit term "net 30" (i.e., $M=30$ days) is offered by the supplier, $I_{V p}=0.04 / \$ /$ year, $I_{B e}=0.09 / \$ /$ year, and $I_{B p}=0.10 / \$ /$ year. In addition, per shipment from the company to the client is assessed a fixed cost $h=\$ 200 /$ shipment and a variable cost $w=\$ 0.5 /$ unit. In addition, all shipments on orders equal to or over $\psi=900$ units are shipped free of charge. Summary of other parameters used is as follows: $a=100000, \delta=1.5, \rho=0.95$, $c_{0}=4.75, \theta=2, \gamma=1.5, \beta=1.52, S_{V}=\$ 1000 /$ setup, $S_{B}=\$ 200 /$ order, $r_{V}=0.05$, and $r_{B}=0.1$.

After running the basic set of parameters, the computational results are that the buyer charges his /her customers a retail price $p^{*}=\$ 12.8258 /$ unit, the optimal replenishment cycle length is $T^{*}=T_{2}=0.4170$ per year and the demand rate is $D\left(p^{*}\right)=a\left(p^{*}\right)^{-\delta}=2177$ units $/$ year. The optimal lot size $Q^{*}=D\left(p^{*}\right) T^{*}=908$ units per order which is over the minimum boundary of free deliveries, so the shipping cost $h+w Q^{*}=\$ 654$ per shipment will be paid by the supplier. Under this condition, the buyer's annual total profit is $\$ 7653$. Per production run, the supplier spends $c=c_{0} D^{-\beta} R^{\gamma}=\$ 4.3990 /$ unit to produce the items at rate $R=D / \rho=2,292$ units/year and sells them at a wholesale price $v=\theta c=\$ 8.7979 /$ unit to the buyer. As there are 16 deliveries from the supplier to the buyer per production run, the supplier's annual total profit is $\$ 7490$, and the maximumjoint total annual profit $\Pi^{*}\left(n^{*}, p^{*}, T^{*}\right)=\Pi^{*}(16,12.8258,0.4170)=\$ 15143$.

When $p$ and $T$ are decision variables, the surface generated by the total profit function $\Pi(16, p, T)$ over a wide range of values of $p$ and $T$ is shown in Figure 2. The graph is drawn using MATHEMATICA 4.0. Furthermore, we show the numerical results with values of $n=1,2, \ldots, 200$. The numerical results indicate that there is a unique integer $n$ which maximizes the value of $\Pi(n) \equiv \Pi^{(n)}\left(n, p^{(n)}, T^{(n)}\right)$, as shown in Figure 3. Consequently, the solution obtained through this Algorithm is the optimal solution.

Example 4.2. Using the same data as in Example 4.1, we investigate some values of $M$ to analyze the effects of credit period on performance. Consider $M \in\{0,10,30,45,60,75,90\}$, the optimal solutions obtained through this Algorithm are presented in Table 2. To illustrate the relationship between credit terms and profit progress, we also demonstrate profit gain (comparing with no trade credit, i.e., $M=0$ ) in percentage in the last three columns of Table 2. We define the profit gain $=[$ (profit with trade credit - profit without trade credit $) /$ profit without trade credit] $\times 100 \%$. 


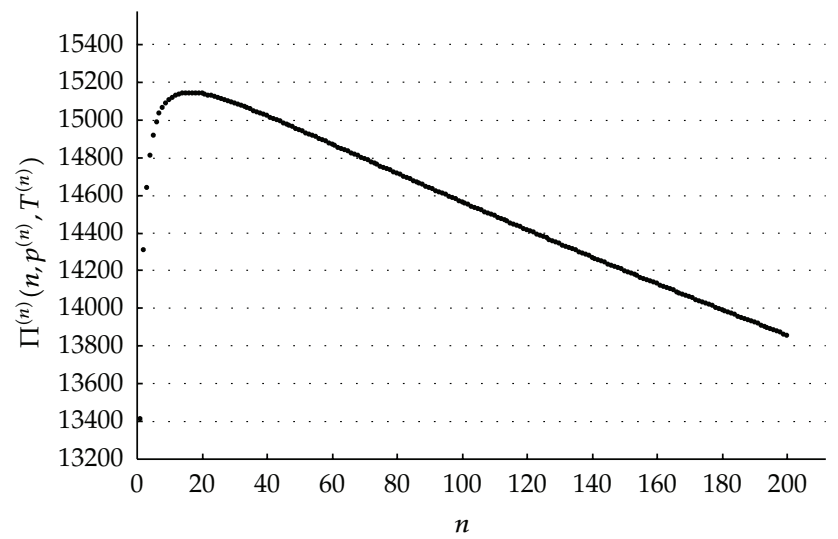

Figure 3: The optimal total profit per unit time for $n=1,2, \ldots, 200$.

Table 2: Influence of optimal solution with different $M$ values.

\begin{tabular}{|c|c|c|c|c|c|c|c|c|c|c|c|c|c|}
\hline \multirow{2}{*}{\multicolumn{2}{|c|}{$M n^{*}$}} & \multirow{2}{*}{$p^{*}$} & \multirow{2}{*}{$c$} & \multirow{2}{*}{$T^{*}$} & \multirow{2}{*}{$D^{*}$} & \multirow{2}{*}{$Q^{*}$} & \multirow{2}{*}{$I_{A}(Q)$} & \multirow{2}{*}{$T V P$} & \multirow{2}{*}{ TBP } & \multirow{2}{*}{$\Pi$} & \multicolumn{3}{|c|}{ Profit gain in percentage $(\%)$} \\
\hline & & & & & & & & & & & Supplier & Buyer & Channel \\
\hline 0 & 16 & 12.9322 & 4.4001 & $T_{2}=0.4205$ & 2150 & 904 & 0 & 7457 & 7614 & 15071 & - & - & - \\
\hline 10 & 16 & 12.8936 & 4.3997 & $T_{2}=0.4194$ & 2160 & 906 & 0 & 7471 & 7622 & 15093 & 0.19 & 0.11 & 0.15 \\
\hline 30 & 16 & 12.8258 & 4.3990 & $T_{2}=0.4170$ & 2177 & 908 & 0 & 7490 & 7653 & 15143 & 0.44 & 0.51 & 0.48 \\
\hline 45 & 16 & 12.7832 & 4.3985 & $T_{2}=0.4149$ & 2188 & 908 & 0 & 7497 & 7689 & 15186 & 0.53 & 0.99 & 0.76 \\
\hline 60 & 17 & 12.7483 & 4.3982 & $T_{2}=0.4091$ & 2197 & 899 & 1 & 9080 & 6153 & 15233 & 21.76 & -19.19 & 1.07 \\
\hline 75 & 17 & 12.7207 & 4.3979 & $T_{2}=0.4065$ & 2104 & 896 & 1 & 9079 & 6206 & 15285 & 21.74 & -18.50 & 1.42 \\
\hline 90 & 17 & 12.7008 & 4.3977 & $T_{2}=0.4036$ & 2209 & 892 & 1 & 9070 & 6271 & 15341 & 21.62 & -17.63 & 1.79 \\
\hline
\end{tabular}

Table 2 shows the optimal retail price $p^{*}$ and replenishment cycle length $T^{*}$ decreases when the credit period $M$ is increasing. However, the optimal order quantities $Q^{*}$ increase first then drop. Observe from Table 2 that as the credit period $M$ increases, the profit gains in percentage are positive for the supplier and entire supply chain system, but are not always positive for the buyer. These results reveal that a larger credit period may motivate the buyer to order a smaller quantity and shorten the replenishment cycle length in order to take advantages of the trade credit more frequently. Yet, if the buyer orders less than $\psi(=900$ units), shipping costs will be charged. The result indicates that when a firm faces a trade-off between trade credit and free-freight order, receiving a trade credit is not always a good idea.

Example 4.3. Here we examine the issue of how sensitive the performances of the supply chain are to the supplier's capacity utilization parameter $\rho$. Using the same data as in Example 4.1 except the value of $\rho$ belongs to the set $\{0.95,0.75,0.50,0.25\}$. The results are reported in Table 3.

Table 3 indicates that the lower the supplier's capacity utilization, that is, the greater inefficient production in the supply chain, the higher production cost. The increasing cost in production leads to rising retail price which in turn reduces market demand and drop profits of the supply chain system. Therefore, while the value of $\rho$ decreases, the expected profits per unit time of the buyer and the entire supply chain decrease. On the other hand, the supplier's 
Table 3: Influence of optimal solution with different $\rho$ values.

\begin{tabular}{lcccccccccc}
\hline$\rho$ & $n^{*}$ & $p^{*}$ & $c$ & $T^{*}$ & $D^{*}$ & $Q^{*}$ & $I_{A}(Q)$ & $T V P$ & $T B P$ & $\Pi$ \\
\hline 0.95 & 16 & 12.8258 & 4.3990 & $T_{2}=0.4170$ & 2177 & 908 & 0 & 7490 & 7653 & 15143 \\
0.75 & 7 & 17.3946 & 6.3287 & $T_{2}=0.4539$ & 1378 & 626 & 1 & 7951 & 4314 & 12264 \\
0.50 & 5 & 30.2920 & 11.8217 & $T_{2}=0.5200$ & 600 & 312 & 1 & 6245 & 2299 & 8544 \\
0.25 & 4 & 80.8479 & 34.4361 & $T_{2}=0.6625$ & 138 & 91 & 1 & 3976 & 425 & 4401 \\
\hline
\end{tabular}

Table 4: Computation results for various values of $\beta(\gamma=1.5)$.

\begin{tabular}{cccccccccccc}
\hline$\beta$ & $n^{*}$ & $p^{*}$ & $v$ & $c$ & $T^{*}$ & $D^{*}$ & $Q^{*}$ & $I_{A}(Q)$ & $T V P$ & $T B P$ & $\Pi$ \\
\hline 1.52 & 16 & 12.8258 & 8.7979 & 4.3990 & $T_{2}=0.4170$ & 2177 & 908 & 0 & 7490 & 7653 & 15143 \\
1.53 & 16 & 11.8692 & 8.1187 & 4.0594 & $T_{2}=0.4095$ & 2445 & 1002 & 0 & 7687 & 8039 & 15726 \\
1.54 & 16 & 10.9690 & 7.4739 & 3.7370 & $T_{2}=0.4023$ & 2753 & 1107 & 0 & 7873 & 8471 & 16344 \\
1.55 & 16 & 10.1240 & 6.8634 & 3.4317 & $T_{2}=0.3952$ & 3104 & 1227 & 0 & 8045 & 8955 & 17000 \\
1.56 & 16 & 9.3332 & 6.2870 & 3.1435 & $T_{2}=0.3885$ & 3507 & 1362 & 0 & 8195 & 9500 & 17695 \\
1.57 & 16 & 8.5952 & 5.7443 & 2.8721 & $T_{2}=0.3820$ & 3968 & 1516 & 0 & 8318 & 10114 & 18432 \\
1.58 & 16 & 7.9088 & 5.2349 & 2.6175 & $T_{2}=0.3758$ & 4496 & 1690 & 0 & 8406 & 10806 & 19212 \\
1.59 & 16 & 7.2724 & 4.7584 & 2.3792 & $T_{2}=0.3701$ & 5099 & 1887 & 0 & 8450 & 11588 & 20038 \\
1.60 & 16 & 6.6845 & 4.3142 & 2.1571 & $T_{2}=0.3648$ & 5786 & 2111 & 0 & 8438 & 12471 & 20909 \\
1.61 & 16 & 6.1433 & 3.9014 & 1.9507 & $T_{2}=0.3599$ & 6567 & 2364 & 0 & 8361 & 13466 & 21827 \\
1.62 & 16 & 5.6469 & 3.5194 & 1.7597 & $T_{2}=0.3556$ & 7452 & 2650 & 0 & 8206 & 14586 & 22793 \\
1.63 & 16 & 5.1935 & 3.1670 & 1.5835 & $T_{2}=0.3519$ & 8449 & 2974 & 0 & 7961 & 15844 & 23805 \\
1.64 & 16 & 4.7809 & 2.8434 & 1.4217 & $T_{2}=0.3489$ & 9566 & 3338 & 0 & 7612 & 17249 & 24862 \\
1.65 & 16 & 4.4069 & 2.5472 & 1.2736 & $T_{2}=0.3466$ & 10809 & 3747 & 0 & 7149 & 18812 & 25961 \\
\hline
\end{tabular}

expected profits per unit time increase first then drop. This results from free shipping offered by the supplier with an order amount over 900 units as $\rho=0.95$. The managerial implication of the result is that if the supplier can obtain the demand information of final customers through the buyer, then he/she may employ the information to adjust his/her production to meet this demand and optimize the entire supply chain.

Example 4.4. Following assumptions (5) in Section 2, the supplier's unit production cost is directly related to the production rate $R$ and inversely related to demand rate $D$, which is given by $c(D, R)=c_{0} D^{-\beta} R^{r}$. To understand the effect of various values of $\gamma$ and $\beta$ on the channel performance, using the same parameter values as in Example 4.1, we apply the Algorithm to obtain the optimal solutions. The results are shown in Tables 4 and 5 .

From Table 4, we can see that for a certain value $\gamma(=1.5)$, increasing $\beta$ leads to a higher order size as well profit gains for the buyer and entire channel. However, with the increase in $\beta$, the supplier's profit increases first then drops. The results indicate that, while unit production cost is sensitive to market demand rate, the supplier will make a mass production to reduce unit production cost. A decrease retail price resulting from lower unit production cost yields an increase in market demand increase. Then the buyer's profit gain increases with an upward market demand. On the other hand, though the supplier can reduce unit production cost by producing in large batches, however, the holding costs also increase with large production quantity. Consequently, a larger production lot size is not always more beneficial for the supplier. 
Table 5: Computation results for various values of $\gamma(\beta=1.52)$.

\begin{tabular}{lccccccccccc}
\hline$r$ & $n^{*}$ & $p^{*}$ & $v$ & $c$ & $T^{*}$ & $D^{*}$ & $Q^{*}$ & $I_{A}(Q)$ & $T V P$ & $T B P$ & $\Pi$ \\
\hline 1.37 & 16 & 4.3842 & 2.5274 & 1.2637 & $T_{2}=0.3466$ & 10893 & 3776 & 0 & 7106 & 18937 & 26044 \\
1.38 & 16 & 4.7574 & 2.8230 & 1.4115 & $T_{2}=0.3489$ & 9637 & 3362 & 0 & 7579 & 17357 & 24936 \\
1.39 & 16 & 5.1695 & 3.1464 & 1.5732 & $T_{2}=0.3519$ & 8508 & 2994 & 0 & 7936 & 15935 & 23871 \\
1.40 & 16 & 5.6227 & 3.4986 & 1.7493 & $T_{2}=0.3555$ & 7500 & 2667 & 0 & 8189 & 14662 & 22851 \\
1.41 & 16 & 6.1191 & 3.8809 & 1.9405 & $T_{2}=0.3598$ & 6607 & 2377 & 0 & 8350 & 13529 & 21878 \\
1.42 & 16 & 6.6607 & 4.2942 & 2.1471 & $T_{2}=0.3646$ & 5817 & 2121 & 0 & 8431 & 12522 & 20953 \\
1.43 & 16 & 7.2496 & 4.7394 & 2.3697 & $T_{2}=0.3699$ & 5123 & 1895 & 0 & 8446 & 11629 & 20075 \\
1.44 & 16 & 7.8873 & 5.2171 & 2.6086 & $T_{2}=0.3757$ & 4514 & 1696 & 0 & 8405 & 10838 & 19243 \\
1.45 & 16 & 8.5756 & 5.7282 & 2.8641 & $T_{2}=0.3819$ & 3982 & 1521 & 0 & 8318 & 10138 & 18456 \\
1.46 & 16 & 9.3161 & 6.2730 & 3.1365 & $T_{2}=0.3884$ & 3517 & 1366 & 0 & 8196 & 9518 & 17714 \\
1.47 & 16 & 10.1101 & 6.8521 & 3.4261 & $T_{2}=0.3952$ & 3111 & 1229 & 0 & 8046 & 8967 & 17013 \\
1.48 & 16 & 10.9589 & 7.4658 & 3.7329 & $T_{2}=0.4022$ & 2756 & 1109 & 0 & 7874 & 8478 & 16353 \\
1.49 & 16 & 11.8638 & 8.1144 & 4.0572 & $T_{2}=0.4095$ & 2447 & 1002 & 0 & 7688 & 8042 & 15730 \\
1.50 & 16 & 12.8258 & 8.7979 & 4.3990 & $T_{2}=0.4170$ & 2177 & 908 & 0 & 7490 & 7653 & 15143 \\
\hline
\end{tabular}

Furthermore, it can be noted from Table 5 that the optimal order sizes decline with the increase in $\gamma$ for a specific $\beta(=1.52)$. In addition, profits for the buyer and entire channel decrease but increase first then drop for the supplier. Since the unit production cost increases with $\gamma$, therefore, higher unit wholesale price and retail price are required. As expected, the increasing retail price significantly reduces market demand significantly resulting in lower total profit for the buyer. On the other hand, first the supplier's profit goes up with the increasing wholesale price, however, as the demand level falls below its desired target this leads to a much lower annual profit for the supplier.

Example 4.5. The purpose of this example is to evaluate the relative performances for various values of the problem parameters. The study was conducted for different values of $h, w$, and $r_{B} / r_{V}$. With the exception of the selected parameters, the values of other parameters have been kept the same as in Example 4.1. The optimal policy maximizing the channel's profit for the various problem parameters is reported in Table 6.

From Table 6, it is observed that as the value of $r_{B} / r_{V}$ increases, that is, as the relative carrying cost rate (excluding interest charge) for the buyer increases, the buyer will order a smaller lot size within a shorter inventory cycle, so more replenishments for each production run (higher value of $n$ ) are required. While the value of $w$ increases (i.e., the relative unit shipping cost increases), the buyer will order a smaller lot size within a longer inventory cycle in order to save cost while selling the items to customers at a higher retail price. Also, the entire channel's expected total profit reduces as the ratio $r_{B} / r_{V}$ and $w$ increase. Finally, Table 6 shows with the increase in $h$ the replenishment cycle and lot size both increase first then decrease. And the number of shipments from the supplier to the buyer and channel profit decrease first then increase.

\section{Conclusion}

In this paper, we consider a single-supplier single/buyer supply chain problem where the production rate of the supplier is assumed to be linearly related to the market demand rate, 
Table 6: The results of sensitivity analysis.

\begin{tabular}{|c|c|c|c|c|c|c|c|c|c|c|c|c|c|}
\hline$r_{B} / r_{V}$ & $h$ & $w$ & $n^{*}$ & $p^{*}$ & c & $v$ & $T^{*}$ & $D^{*}$ & $Q^{*}$ & $I_{A}(Q)$ & $T V P$ & TBP & $\Pi$ \\
\hline \multirow{9}{*}{1} & 50 & 0.1 & 19 & 12.0406 & 4.3906 & 8.7813 & $T_{2}=0.3504$ & 2393 & 839 & 1 & 9983 & 6473 & 16456 \\
\hline & & 0.5 & 19 & 13.1982 & 4.4027 & 8.8055 & $T_{2}=0.3746$ & 2086 & 781 & 1 & 8695 & 7092 & 15787 \\
\hline & & 0.9 & 19 & 14.3547 & 4.4139 & 8.8277 & $T_{2}=0.3982$ & 1839 & 732 & 1 & 7661 & 7535 & 15196 \\
\hline & 200 & 0.1 & 15 & 11.8179 & 4.3882 & 8.7764 & $T_{2}=0.4382$ & 2461 & 1079 & 0 & 9524 & 6501 & 16025 \\
\hline & & 0.5 & 15 & 12.9599 & 4.4003 & 8.8007 & $T_{2}=0.4687$ & 2143 & 1005 & 0 & 7401 & 7984 & 15385 \\
\hline & & 0.9 & 15 & 14.1011 & 4.4115 & 8.8230 & $T_{2}=0.4985$ & 1889 & 941 & 0 & 5733 & 9086 & 14819 \\
\hline & 400 & 0.1 & 21 & 12.1258 & 4.3916 & 8.7831 & $T_{2}=0.3173$ & 2368 & 751 & 1 & 9892 & 6721 & 16614 \\
\hline & & 0.5 & 21 & 13.2893 & 4.4037 & 8.8073 & $T_{2}=0.3390$ & 2064 & 700 & 1 & 8619 & 7314 & 15934 \\
\hline & & 0.9 & 21 & 14.4516 & 4.4147 & 8.8295 & $T_{2}=0.3603$ & 1820 & 656 & 1 & 7597 & 7737 & 15334 \\
\hline \multirow{9}{*}{2} & 50 & 0.1 & 21 & 11.9396 & 4.3895 & 8.7791 & $T_{2}=0.3109$ & 2424 & 754 & 1 & 10126 & 6133 & 16259 \\
\hline & & 0.5 & 21 & 13.0898 & 4.4017 & 8.8033 & $T_{2}=0.3324$ & 2112 & 702 & 1 & 8819 & 6785 & 15603 \\
\hline & & 0.9 & 21 & 14.2390 & 4.4128 & 8.8256 & $T_{2}=0.3534$ & 1861 & 658 & 1 & 7769 & 7254 & 15024 \\
\hline & 200 & 0.1 & 16 & 11.6930 & 4.3868 & 8.7736 & $T_{2}=0.3898$ & 2501 & 975 & 0 & 9649 & 6117 & 15766 \\
\hline & & 0.5 & 16 & 12.8258 & 4.3990 & 8.7979 & $T_{2}=0.4170$ & 2177 & 908 & 0 & 7490 & 7653 & 15143 \\
\hline & & 0.9 & 16 & 13.9579 & 4.4101 & 8.8203 & $T_{2}=0.4436$ & 1918 & 851 & 1 & 7974 & 6619 & 14592 \\
\hline & 400 & 0.1 & 23 & 12.0342 & 4.3906 & 8.7811 & $T_{2}=0.2822$ & 2395 & 676 & 1 & 10020 & 6419 & 16439 \\
\hline & & 0.5 & 23 & 13.1909 & 4.4027 & 8.8053 & $T_{2}=0.3016$ & 2087 & 630 & 1 & 8729 & 7041 & 15771 \\
\hline & & 0.9 & 23 & 14.3466 & 4.4138 & 8.8276 & $T_{2}=0.3206$ & 1840 & 590 & 1 & 7693 & 7488 & 15181 \\
\hline \multirow{9}{*}{3} & 50 & 0.1 & 23 & 11.8499 & 4.3885 & 8.7771 & $T_{2}=0.2816$ & 2451 & 690 & 1 & 10254 & 5825 & 16079 \\
\hline & & 0.5 & 23 & 12.9934 & 4.4007 & 8.8014 & $T_{2}=0.3010$ & 2135 & 643 & 1 & 8929 & 6507 & 15435 \\
\hline & & 0.9 & 23 & 14.1360 & 4.4118 & 8.8236 & $T_{2}=0.3200$ & 1882 & 602 & 1 & 7865 & 7001 & 14866 \\
\hline & 200 & 0.1 & 18 & 11.5824 & 4.3855 & 8.7711 & $T_{2}=0.3512$ & 2537 & 891 & 1 & 10578 & 4949 & 15527 \\
\hline & & 0.5 & 18 & 12.7070 & 4.3977 & 8.7955 & $T_{2}=0.3757$ & 2208 & 829 & 1 & 9202 & 5720 & 14921 \\
\hline & & 0.9 & 18 & 13.8311 & 4.4089 & 8.8179 & $T_{2}=0.3997$ & 1944 & 777 & 1 & 8099 & 6286 & 14385 \\
\hline & 400 & 0.1 & 25 & 11.9526 & 4.3897 & 8.7793 & $T_{2}=0.2560$ & 2420 & 619 & 1 & 10134 & 6145 & 16279 \\
\hline & & 0.5 & 25 & 13.1033 & 4.4018 & 8.8036 & $T_{2}=0.2736$ & 2108 & 577 & 1 & 8827 & 6794 & 15622 \\
\hline & & 0.9 & 25 & 14.2530 & 4.4129 & 8.8258 & $T_{2}=0.2908$ & 1858 & 540 & 1 & 7779 & 7262 & 15041 \\
\hline
\end{tabular}

while demand is sensitive to retail price. The wholesale price imposed by the supplier on the buyer is based on his/her unit production cost which is determined by the market demand rate and production rate. The supplier produces one product in batches and periodically delivers the product at a fixed lot size to the buyer. In addition, to encourage the retailer to order more, the supplier offers a trade credit and a quantity-dependent free freight. By analyzing the total channel profit function, we then developed a solution algorithm to determine the optimal retail price, replenishment cycle length and the number of shipments per production cycle from the supplier to the buyer. Numerical examples are presented to illustrate this model. Comprehensive sensitivity analyses for the effects of the parameters on the optimal solutions are also offered.

The following observations could be made from the numerical examples. First, when the buyer faces a trade-off between ordering a smaller quantity to take advantages of the trade credit more frequently against ordering a larger quantity to take advantages of free shipping, he/she must carefully weigh the pros of each. Second, it is found that if the supplier can acquire "real time" market demand rate from the buyer and adjust production rate to 
match, this not only helps to reduce production cost for the supplier but also increases the profit gain for the entire supply chain. Finally, the result indicates that a larger production lot size is not always more economical for the supplier. It is because though the supplier can achieve economies of scale by producing in large batches, however, his/her holding and transportation costs also increase with a large order quantity.

As for future research, our model can be extended to more general supply chain networks, for example, multiechelon or assembly supply chains. Also, it is interesting to consider deteriorating items into the proposed model.

\section{Notation and Assumptions}

The following notations are adopted throughout this paper:

$R$ : Supplier's production rate.

$S_{V}$ : Supplier's setup cost per setup.

$S_{B}$ : Buyer's ordering cost per order.

$r_{V}$ : Supplier's holding cost rate, excluding interest charges.

$r_{B}$ : Buyer's holding cost rate, excluding interest charges.

c: Supplier's unit production cost.

$v$ : Supplier's unit wholesale price.

$p$ : Buyer's unit retail price (decision variable).

$D$ : Market demand rate for the product.

M: Buyer's credit period offered by the supplier per order.

$I_{V p}$ : Supplier's capital opportunity cost per dollar per unit time.

$I_{B p}$ : Buyer's capital opportunity cost per dollar per unit time.

$I_{B e}$ : Buyer's interest earned per dollar per unit time.

$n$ : Number of shipments from supplier to buyer per production run, a positive integer (decision variable).

$T$ : Buyer's replenishment cycle length (decision variable).

$Q$ : Buyer's order quantity per order (decision variable).

$h$ : Fixed shipping cost per delivery.

$w$ : Unit shipping cost.

TVP: The supplier's expected total profit per unit time.

TBP: The buyer's expected total profit per unit time.

П: The channel's expected total profit per unit time.

In addition, the following assumptions are made in deriving the model.

(1) There is single supplier and single buyer for a single product.

(2) Shortages are not permitted. 
(3) The market demand rate for the product is assumed sensitive to the buyer's selling price $p$ and is given by $D(p)=a p^{-\delta}$, where $a>0$ is a scaling factor, and $\delta>0$ is a price-elasticity coefficient. For notational simplicity, $D(p)$ and $D$ will be used interchangeably in this paper.

(4) The supplier's capacity utilization, $\rho$, is the ratio of the demand rate, $D$, to the production rate, $R$, which is given as less than 1 , that is, $\rho=D / R$ and $\rho<1$.

(5) The supplier's unit production cost is directly related to the production rate $R$ and inversely related to demand rate $D$, which is given by $c(D, R)=c_{0} D^{-\beta} R^{r}$, where $c_{0}, \beta$ and $\gamma$ are nonnegative real numbers and satisfy $0<\beta-\gamma<1$. Similar assumption has been considered in Cheng [47]. For notational simplicity, $c(D, R)$ and $c$ will be used interchangeably in this paper.

(6) Each unit is produced for $\$ c$ and sold $\$ v$ to the buyer, where $v=\theta c, \theta>1$. Afterward, each unit is sold by the buyer on the market for $\$ p(>v)$.

(7) The buyer's replenishment cycle length is $T$ and order quantity is $Q(=D T)$ per order.

(8) The supplier manufactures, at rate $R$, in batches of sizes of $n Q$ and incurs a batch set up cost $S_{V}$. Each batch is dispatched to the buyer in $n$ equal size shipments.

(9) Per shipment from the supplier to the buyer is assessed a fixed cost $h$ that includes insurance on consignment invoice value, trucking costs, and a variable cost $w$ for the unit shipping. In addition, free shipping is offered when the amount ordered reaches the minimum amount $\psi$. That is the buyer's transportation cost per order is $I_{A}(Q)(h+w Q)$, where $I_{A}(Q)$ is the indicator function of $Q$ with $I_{A}(Q)=1$, if $Q \in A=\{Q \mid Q<\psi\} ; I_{A}(Q)=0$ if $Q \notin \mathrm{A}$.

(10) During the credit period, the buyer sells the items and uses the sales revenue to earn interest at a rate of $I_{B e}$. At the end of the permissible delay period, the buyer pays the purchasing cost to the supplier and incurs an opportunity cost at a rate of $I_{B p}$ for the items in stock.

\section{Acknowledgments}

The author is grateful to the anonymous referee for his/her valuable and helpful suggestions on an earlier version of the paper. This research was supported by the National Science Council of the Republic of China under Grant NSC 97-2410-H-236-001.

\section{References}

[1] F. W. Harris, “How many parts to make at once," The Magazine of Management, vol. 10, pp. 135-136, 1913.

[2] P. J. Schweitzer and A. Seidmann, "Optimizing processing rates for flexible manufacturing systems," Management Science, vol. 37, no. 4, pp. 454-466, 1991.

[3] A. Goswami and K. S. Chaudhuri, "Variations of order-level inventory models for deteriorating items," International Journal of Production Economics, vol. 27, no. 2, pp. 111-117, 1992.

[4] Z. T. Balkhi and L. Benkherouf, "A production lot size inventory model for deteriorating items and arbitrary production and demand rates," European Journal of Operational Research, vol. 92, no. 2, pp. 302-309, 1996. 
[5] S. K. Goyal and B. C. Giri, "The production-inventory problem of a product with time varying demand, production and deterioration rates," European Journal of Operational Research, vol. 147, no. 3, pp. 549-557, 2003.

[6] A. K. Bhunia and M. Maiti, "Deterministic inventory models for variable production," Journal of the Operational Research Society, vol. 48, no. 2, pp. 221-224, 1997.

[7] A. Kalir and Y. Arzi, "Optimal design of flexible production lines with unreliable machines and infinite buffers," IIE Transactions, vol. 30, no. 4, pp. 391-399, 1998.

[8] M. A. Rahim and M. Ben-Daya, "Joint determination of production quantity, inspection schedule, and quality control for an imperfect process with deteriorating products," Journal of the Operational Research Society, vol. 52, no. 12, pp. 1370-1378, 2001.

[9] B. C. Giri, W. Y. Yun, and T. Dohi, “Optimal design of unreliable production-inventory systems with variable production rate," European Journal of Operational Research, vol. 162, no. 2, pp. 372-386, 2005.

[10] S. Öner and T. Bilgiç, "Economic lot scheduling with uncontrolled co-production," European Journal of Operational Research, vol. 188, no. 3, pp. 793-810, 2008.

[11] J. Li, S. Wang, and T. C. E. Cheng, "Analysis of postponement strategy by EPQ-based models with planned backorders," Omega, vol. 36, no. 5, pp. 777-788, 2008.

[12] R. J. Tersine and R. A. Toelle, "Lot size determination with quantity discounts," Production E Inventory Management, vol. 26, no. 3, pp. 1-23, 1985.

[13] C. Y. Lee, "The economic order quantity for freight discount costs," IIE Transactions, vol. 18, no. 3, pp. 318-320, 1986.

[14] H. Hwang, D. H. Moon, and S. W. Shinn, "An EOQ model with quantity discounts for both purchasing price and freight cost," Computers and Operations Research, vol. 17, no. 1, pp. 73-78, 1990.

[15] R. J. Tersine and S. Barman, "Optimal lot sizes for unit and shipping discount situations," IIE Transactions, vol. 26, no. 2, pp. 97-101, 1994.

[16] R. M. Russell and L. Krajewski, "Optimal purchase and transportation cost lot sizing on a single item," Decision Science, vol. 22, pp. 940-952, 1991.

[17] S. W. Shinn, H. Hwang, and S. S. Park, "Joint price and lot size determination under conditions of permissible delay in payments and quantity discounts for freight cost," European Journal of Operational Research, vol. 91, no. 3, pp. 528-542, 1996.

[18] S. R. Swenseth and M. R. Godfrey, "Incorporating transportation costs into inventory replenishment decisions," International Journal of Production Economics, vol. 77, no. 2, pp. 113-130, 2002.

[19] P. L. Abad and V. Aggarwal, "Incorporating transport cost in the lot size and pricing decisions with downward sloping demand," International Journal of Production Economics, vol. 95, no. 3, pp. 297-305, 2005.

[20] B. Q. Rieksts and J. A. Ventura, "Optimal inventory policies with two modes of freight transportation," European Journal of Operational Research, vol. 186, no. 2, pp. 576-585, 2008.

[21] S. Mateut, S. Bougheas, and P. Mizen, "Trade credit, bank lending and monetary policy transmission," European Economic Review, vol. 50, no. 3, pp. 603-629, 2006.

[22] A. Guariglia and S. Mateut, "Credit channel, trade credit channel, and inventory investment: Evidence from a panel of UK firms," Journal of Banking and Finance, vol. 30, no. 10, pp. 2835-2856, 2006.

[23] Y. Ge and J. Qiu, "Financial development, bank discrimination and trade credit," Journal of Banking and Finance, vol. 31, no. 2, pp. 513-530, 2007.

[24] S. K. Goyal, "Economic order quantity under conditions of permissible delay in payments," Journal of the Operational Research Society, vol. 36, no. 4, pp. 335-338, 1985.

[25] S. P. Aggarwal and C. K. Jaggi, "Ordering policies of deteriorating items under permissible delay in payments," Journal of the Operational Research Society, vol. 46, pp. 658-662, 1995.

[26] A. M. M. Jamal, B. R. Sarker, and S. Wang, "An ordering policy for deteriorating items with allowable shortage and permissible delay in payment," Journal of the Operational Research Society, vol. 48, no. 8, pp. 826-833, 1997.

[27] H.-J. Chang and C.-Y. Dye, "An inventory model for deteriorating items with partial backlogging and permissible delay in payments," International Journal of Systems Science, vol. 32, no. 3, pp. 345-352, 2001.

[28] J.-T. Teng, "On the economic order quantity under conditions of permissible delay in payments," Journal of the Operational Research Society, vol. 53, no. 8, pp. 915-918, 2002.

[29] F. J. Arcelus, N. H. Shah, and G. Srinivasan, "Retailer's pricing, credit and inventory policies for deteriorating items in response to temporary price/credit incentives," International Journal of Production Economics, vol. 81-82, pp. 153-162, 2003. 
[30] D. Biskup, D. Simons, and H. Jahnke, "The effect of capital lockup and customer trade credits on the optimal lot size-a confirmation of the EPQ," Computers and Operations Research, vol. 30, no. 10, pp. 1509-1524, 2003.

[31] C.-T. Chang, L.-Y. Ouyang, and J.-T. Teng, "An EOQ model for deteriorating items under supplier credits linked to ordering quantity," Applied Mathematical Modelling, vol. 27, no. 12, pp. 983-996, 2003.

[32] Y.-F. Huang, "Optimal retailer's replenishment policy for the EPQ model under the supplier's trade credit policy," Production Planning and Control, vol. 15, no. 1, pp. 27-33, 2004.

[33] C.-T. Chang, "An EOQ model with deteriorating items under inflation when supplier credits linked to order quantity," International Journal of Production Economics, vol. 88, no. 3, pp. 307-316, 2004.

[34] K.-J. Chung, S. K. Goyal, and Y.-F. Huang, "The optimal inventory policies under permissible delay in payments depending on the ordering quantity," International Journal of Production Economics, vol. 95, no. 2, pp. 203-213, 2005.

[35] L.-Y. Ouyang, C.-H. Su, and C.-H. Ho, “Optimal strategy for the integrated vendor-buyer inventory model with adjustable production rate and trade credit," International Journal of Information and Management Sciences, vol. 16, no. 4, pp. 19-37, 2005.

[36] J.-T. Teng, C.-T. Chang, and S. K. Goyal, "Optimal pricing and ordering policy under permissible delay in payments," International Journal of Production Economics, vol. 97, no. 2, pp. 121-129, 2005.

[37] K.-J. Chung and J.-J. Liao, "The optimal ordering policy in a DCF analysis for deteriorating items when trade credit depends on the order quantity," International Journal of Production Economics, vol. 100 , no. 1, pp. 116-130, 2006.

[38] S. P. Sarmah, D. Acharya, and S. K. Goyal, "Two-stage supply chain coordination through credit option in asymmetric information environment," International Journal of Logistics Systems and Management, vol. 4, no. 1, pp. 98-115, 2008.

[39] P. L. Abad and C. K. Jaggi, "A joint approach for setting unit price and the length of the credit period for a seller when end demand is price sensitive," International Journal of Production Economics, vol. 83, no. 2, pp. 115-122, 2003.

[40] M. Y. Jaber and I. H. Osman, "Coordinating a two-level supply chain with delay in payments and profit sharing," Computers and Industrial Engineering, vol. 50, no. 4, pp. 385-400, 2006.

[41] P. C. Yang and H. M. Wee, "A collaborative inventory system with permissible delay in payment for deteriorating items," Mathematical and Computer Modelling, vol. 43, no. 3-4, pp. 209-221, 2006.

[42] G.-J. Sheen and Y.-C. Tsao, "Channel coordination, trade credit and quantity discounts for freight cost," Transportation Research Part E, vol. 43, no. 2, pp. 112-128, 2007.

[43] L.-H. Chen and F.-S. Kang, "Integrated vendor-buyer cooperative inventory models with variant permissible delay in payments," European Journal of Operational Research, vol. 183, no. 2, pp. 658-673, 2007.

[44] C.-H. Su, L.-Y. Ouyang, C.-H. Ho, and C.-T. Chang, “Retailer's inventory policy and supplier's delivery policy under two-level trade credit strategy," Asia-Pacific Journal of Operational Research, vol. 24, no. 5, pp. 613-630, 2007.

[45] L.-Y. Ouyang, C.-H. Ho, and C.-H. Su, “Optimal strategy for an integrated system with variable production rate when the freight rate and trade credit are both linked to the order quantity," International Journal of Production Economics, vol. 115, no. 1, pp. 151-162, 2008.

[46] C.-H. Ho, L.-Y. Ouyang, and C.-H. Su, “Optimal pricing, shipment and payment policy for an integrated supplier-buyer inventory model with two-part trade credit," European Journal of Operational Research, vol. 187, no. 2, pp. 496-510, 2008.

[47] T. C. E. Cheng, "An economic order quantity model with demand-dependent unit production cost and imperfect production processes," IIE Transactions, vol. 23, no. 1, pp. 23-28, 1991.

[48] P. Joglekar, "Comments on. A quantity discount pricing model to increase vendor profits," Management Science, vol. 34, pp. 1391-1398, 1988. 


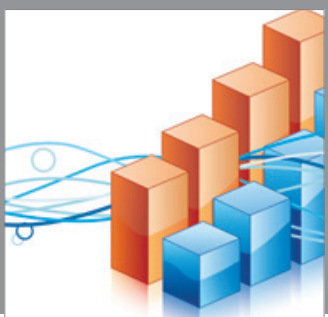

Advances in

Operations Research

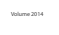

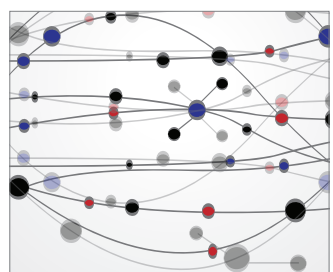

\section{The Scientific} World Journal
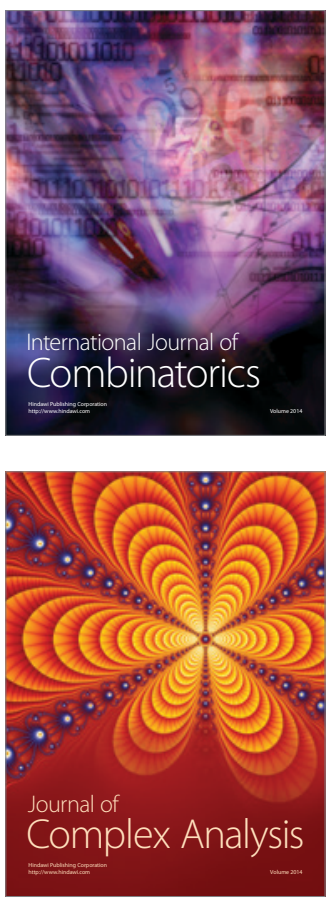

International Journal of

Mathematics and

Mathematical

Sciences
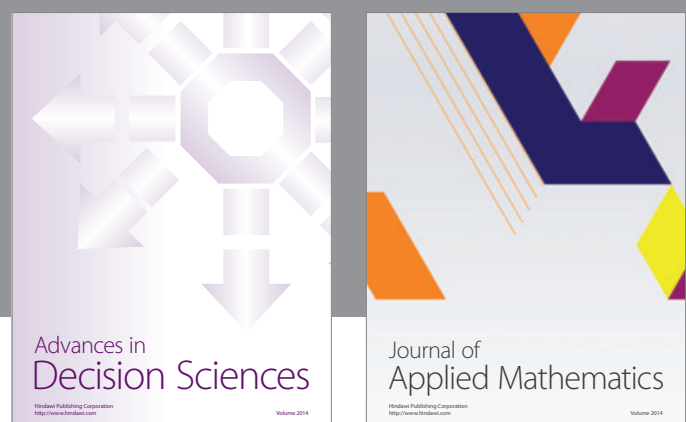

Journal of

Applied Mathematics
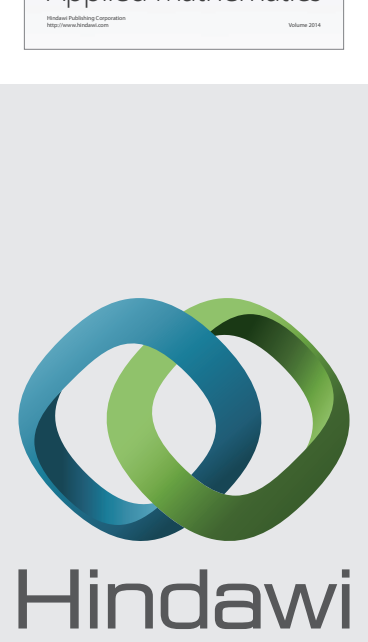

Submit your manuscripts at http://www.hindawi.com
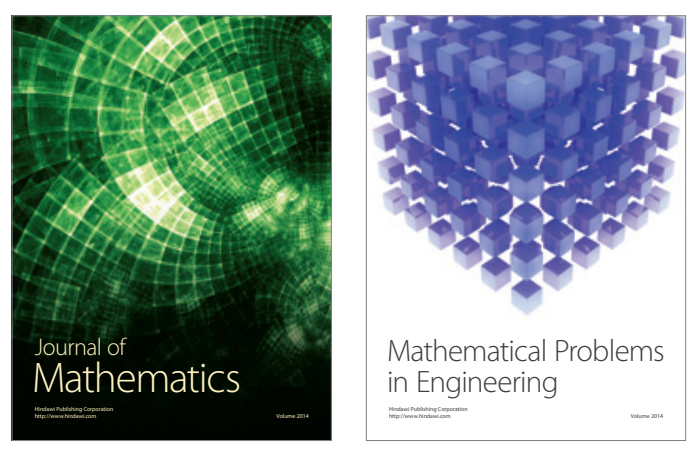

Mathematical Problems in Engineering
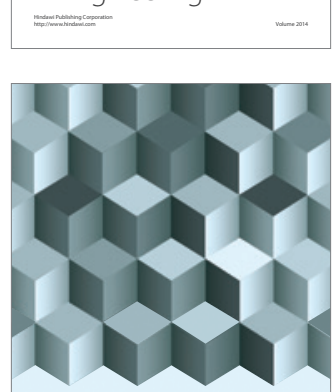

Journal of

Function Spaces
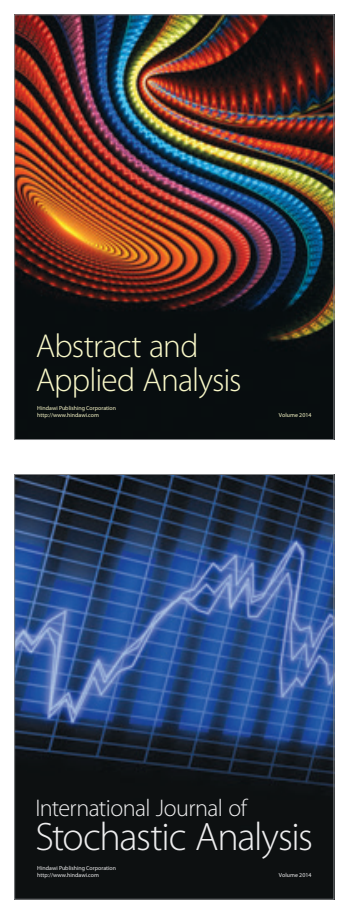

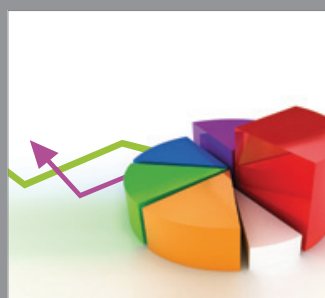

ournal of

Probability and Statistics

Promensencen
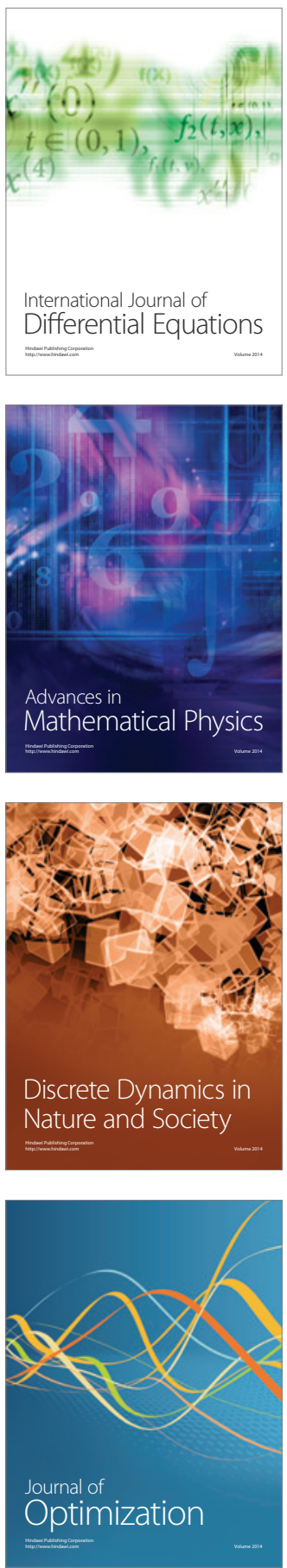